Bol. Mus. Para. Emilio Goeldi. Ciências Naturais, Belém, v. 1, n. 2, p. 113-120, maio-ago. 2006

\title{
Jacaranda copaia (Aubl.) D. Don. subsp. spectabilis (Mart. ex A. DC) Gentry (Bignoniaceae): aspectos morfológicos do fruto, semente, germinação e plântula ${ }^{1}$ \\ Jacaranda copaia (Aubl.) D. Don. subsp. spectabilis (Mart. ex A. DC) Gentry (Bignoniaceae): morphological aspects of fruit, seed and seedling
}

\author{
Ely Simone Cajueiro Gurgel ${ }^{1}$ \\ João Ubiratan Moreira dos Santos ${ }^{1}$ \\ Ana Cristina Magalhães Carvalho II \\ Maria de Nazaré do Carmo Bastos ${ }^{\text {I }}$
}

Resumo: Jacaranda copaia (Aubl.) D. Don. subsp. spectabilis (Mart. ex A. DC) Gentry é a única espécie conhecida como Paraparána Amazônia. Ocorre nas florestas amazônicas de terra-firme, distribuindo-se nos estados do Amazonas, Pará, Mato Grosso, Tocantins, Roraima e boa parte dos estados do sul e do sudeste. A sua madeira é usada, principalmente, para a construção civil. Objetivou-se com este estudo descrever a morfologia do fruto, da semente e da plântula da referida espécie, utilizando-se 30 frutos, 30 sementes e 10 plântulas. Registrou-se a morfologia geral dos frutos, a coloração, a textura, a consistência, a deiscência e o indumento; das sementes, o tegumento e o embrião, bem como os principais elementos vegetativos das plântulas. Considerou-se plântula a fase de desenvolvimento em que os eófilos estavam totalmente formados. Fundamentou-se todo o estudo em literatura especializada e ilustraram-se os principais caracteres morfológicos com fotografias. Apresenta cápsula simples, seca, estenocárpica, elíptica a oblonga, deiscente, pericarpo opaco, imaturo verde e maduro e em tons castanhos quase negro, glabro e cartáceo; pedúnculo opaco, em tons castanhos, superfície glabra e fibrosa; funículo lenhoso e em tons castanhos. Semente alada, estenospérmica, cordiforme; testa monocrômica, em tons castanhos, opaca, esponjosa, superfície glabra; região hilar próxima ao ápice da radícula, hilo punctiforme, heterócromo, castanho mais claro que a testa, em depressão; micrópila não perceptível; tégmen castanho-claro e membranáceo; embrião alargado, axial, foliáceo, invaginado, amarelo, cotilédones crassos, esbranquiçados, dominantes, cordiformes, com ápice profundamente bilobado, margem inteira, base arredondada, auriculado com a radícula exposta; eixo embrionário entre os lóbulos cotiledonares, reto, cônico, espesso, perolado; plúmula amarela, rudimentar. Germinação fanerocotiledonar epígea. Plântula com eófilos trifoliolados, opostos, simétricos, ovais, margem crenada, com pêlos hialinos e simples por todo o limbo, pecíolo canaliculado. Planta jovem com eófilos de $2^{a}$ ordem imparipinados, com cinco folíolos, filotaxia oposta cruzada.

Palavras-chave:Manejo florestal. Silvicultura. Identificação de plâtula. Amazônia.

\footnotetext{
I Museu Paraense Emílio Goeldi. Coordanação de Botânica. Belém, Pará, Brasil (esgurgel@museu-goeldi.br) (bira@museu-goeldi.br) (nazir@museu-goeldi.br).

II Museu Paraense Emilio Goeldi. Coordanação de Botânica. Bolsista de Desenvolvimento Tecnológico Industrial / CNPq. Belém, Pará, Brasil (anitacarval@yahoo.br).

1 Embrapa Amazônia Oriental. Projeto Dendrogene (Conservação Genética nas Florestas Manejadas da Amazônia / DFID).
}

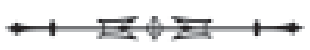


Jacaranda copaia (Aubl.) D. Don. subsp. spectabilis (Mart. ex A. DC) Gentry (Bignoniaceae): aspectos morfológicos...

Abstract: Jacaranda copaia (Aubl.) D. Don. subsp. spectabilis (Mart. ex A. DC) Gentry is the only species known as Parapará in Amazonian, they occur at the Amazonian firm forests, is distributed in the states of Amazon, Pará, Mato Grosso, Tocantins, Roraima, and part of the states of the south and of the southeast. This wood is used mainly for the civil building. This study object was describing the morphology of the fruit, seed and seedlings, was use 30 fruits, 30 seeds and 10 seedlings. Of the fruits was described the general morphology, coloration, texture, consistence, dehiscent and the indumento; of the seeds the tegument and the embryo and the main vegetative elements of the seedling. Was considered seedling the development phase in that the eophylls were totally formed. The whole study was based in specialized literature and the main morphologic characters were illustrated with pictures. The simple capsule is dries, estenocarpic, elliptic the oblong, dehiscent, green and pericarp opaque, immature and in almost black brown tones, glabrous and chartaceous; opaque, in brown tones, surface glabrous and fibrous; woody funiculus in brown tones. Estenospermic seed, cordiformeou; monocromic testa, in brown tones, opaque, spongy, surface glabrous; hilum close to the apex of the radicule, punctiforme hilum, heterocromy, brown light than the testa, in depression; brown light tegmen and membranaceous; enlarged embryo, axial, foliaceous, invaginate, yellow, cotyledon gross, whitish, dominant, cordiformes, with apex deeply bilobate, margin completes, round base, auriculate with the exposed radicule; embryonic axis among the lobes cotyledonate, straight, conical, thick, pearly; yellows plumule, rudimentary. Fanerocotylar epigeous germination. Seedlings with trifoliolate eophylls, opposed, symmetrical, oval, margin crenate, with hair hialinous and simple for the whole limbo, canaliculate peciolous. The saplings has the second order eophylls imparipinate with five foliolous, and crusade leaf arrangment.

Keywords: Forestry management. Silviculture. Seedlings identification. Amazon.

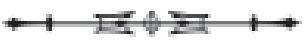




\section{INTRODUÇÃO}

Jacaranda Juss. é um gênero neotropical composto por 49 espécies, distribuindo-se da Guatemala e Antilhas ao Nordeste da Argentina. As folhas são usualmente bipinadas, ocasionalmente pinadas e raramente simples. As inflorescências detêm poucas a muitas flores terminais ou são panículas axilares, raramente racemosas. As flores apresentam um cálice curto e estreitamente campanulado a cupulado, a corola é azul ou azul marinho e a margenta raramente branca (GENTRY; MORAWETZ, 1992).

fruto é originado de um ovário supero, trata-se de uma cápsula oblonga, não equinada, cujas valvas variam de glabras a lepidota, freqüentemente com margens onduladas. O reduzido eixo seminífero não pode servir de apoio para as sementes, como acontece nos demais gêneros, então, há o desenvolvimento de placentas, que permite as sementes se posicionarem de modo perpendicular ao curto eixo e se apoiarem na superfície interna, quase plana, das valvas. Tem-se, então, um fruto no qual a deiscência loculicida é perpendicular ao eixo seminífero, mas com as sementes dispostas paralelamente ao plano de deiscência da cápsula, o que provavelmente deve facilitar a dispersão das sementes. As sementes são finas, apresentando asa membranácea, hialina ou em tons castanhos e núcleo seminífero castanho, são presas pela base, não possuem endosperma e o embrião é mais largo do que longo, os cotilédones são geralmente emarginados e o eixo hipocótilo radícula é curto (GENTRY; MORAWETZ, 1992; BARROSO et al.,1999).

Jacaranda copaia subsp. spectabilis é popularmente conhecida como caroba, manacá, Parapará, caroba do mato, caraúba, carobussu, marupá, simaruba copaia, simaruba falsa e pertence a um grupo ecológico pioneiro que ocorre nas florestas amazônicas de terra firme.

São árvores com cerca de $45 \mathrm{~m}$ de altura por $45 \mathrm{~cm}$ de diâmetro. As folhas são bipinadas de 15 a 165 cm de largura, com 5 a 20 pinas, cada uma com cerca de 5 a $25 \mathrm{~cm}$ de comprimento; a ráquis é essencialmente não alada e com 5 a 25 folíolos sésseis, 1,5 a 8 cm de comprimento e 0,8 a $2,5 \mathrm{~cm}$ de largura; são assimetricamente rombóidais-elípticos, agudos a acuminados, assimetricamente cuneados na base e membranáceos. Os frutos são cápsulas oblongas com margens retas, medindo entre 6,2 e 12,7 cm de comprimento por 3,3 a 6 cm de largura, são lepidotos a glabros, negros ou castanhos escuros e com lenticelas. As sementes apresentam região embrionária com 3 a $5 \mathrm{~mm}$ de largura por 3 a $4 \mathrm{~mm}$ de comprimento. Esta região é circundada por uma asa suborbicular com 1 a $2 \mathrm{~cm}$ de comprimento e 1,7 a 2,8 cm de largura, a asa é hialina, membranácea com estriais radiais, em tons castanhos, que partem da região embrionária (GENTRY; MORAWETZ, 1992).

Na Amazônia, apresenta duas subespécies, diferenciadas pelo formato do folíolo, pois a subespécie copaia (Aubl.) D. Don. apresenta folhas menores, com 5 a 9 pinas, folíolos oblongo-elípticos com a base simétrica, folíolos com peciólulos de 2 a $4 \mathrm{~mm}$, escuros na face abaxial quando desidratados; a subespécie spectabilis (Mart. Ex A. Dc) Gentry apresenta folhas maiores, com 5 a 20 pinas, folíolos rombóideo-elípticos com base assimétrica, folíolos sésseis, apresentando oliva na face abaxial quando desidratados (GENTRY; MORAWETZ, 1992).

Possui uma distribuição que abrange os estados do Amazonas, Pará, Mato Grosso, Tocantins, Roraima, e boa parte dos estados do sul e do sudeste, com destaque para São Paulo, o grande utilizador de sua madeira principalmente para a construção civil (RIBEIRO et al., 1999).

É uma árvore com uma dispersão anemófila, floração entre setembro e outubro e frutificação entre os meses de março e abril (SILVA; LISBOA P.; LISBOA R., 1977).

Segundo Corrêa (1984), o fruto de Jacaranda copaia subsp. spectabilis é capsulado com duas aberturas, apresentando uma forma elíptica oblonga e comprimido em direção perpendicular ao eixo. Possui base e ápice arredondado e levemente obtuso.

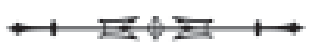


Jacaranda copaia (Aubl.) D. Don. subsp. spectabilis (Mart. ex A. DC) Gentry (Bignoniaceae): aspectos morfológicos...

Por ter aproximadamente $30 \mathrm{~m}$ de altura, e $60 \mathrm{a}$ $90 \mathrm{~cm}$ de diâmetro, é considerada uma árvore de grande porte. Fornece madeira branco-amarelada ou branco-sujo, um pouco acetinada, leve e mole, por isso é considerada ideal para trabalhos no campo da construção civil, principalmente em acabamentos em peças como caxilhos de portas, janelas, pisos, forros etc. Porém, seu uso vai além, sendo utilizado na fabricação de todos os tipos de caixotes de madeira, amarração de balsas e, até mesmo, em móveis diversos e utensílios (CORRÊA, 1984; GENTRY; MORAWETZ, 1992).

Este estudo objetivou descrever e caracterizar a morfologia do fruto, da semente, da germinação e da plântula de Jacaranda copaia subsp. spectabilis, para subsidiar o reconhecimento desta espécie nas formações naturais; embasar futuros trabalhos taxonômicos, filogenéticos e ecológicos; e preparar duas coleções de referência para plântula, as quais foram registradas no herbário do Museu Paraense Emílio Goeldi, Belém, Pará e IAN (herbário da Embrapa Amazônia Oriental, Belém, Pará).

\section{MATERIAL E MÉTODOS}

Coletaram-se frutos maduros, diretamente da copa e no chão sob a matriz, de um espécime existente no campus de pesquisas da Embrapa Amazônia Oriental, Belém, Pará.

Procedeu-se a coleta de material botânico fértil para confecção de exsicatas e identificação. As exsicatas da planta matriz foram incorporadas aos herbários sob os números: MG 168.263 e IAN 176.899 (Gurgel, E.S.C. 12) .

material foi transportado para o laboratório de Botânica da Embrapa Amazônia Oriental, onde os frutos e as sementes foram beneficiados.

Uma subamostra com 30 frutos e 30 sementes foi retirada aleatoriamente para a descrição morfológica. Dos frutos, registrou-se a morfologia geral, classificação, coloração, textura, consistência, posição, a deiscência e o indumento do pericarpo; da semente, analisou-se o tegumento, o endosperma e o embrião. Quanto aos caracteres morfológicos, das sementes foram analisados forma e borda, consistência, cor e textura dos tegumentos, posição do hilo e da micrópila e o embrião quanto ao tipo e forma.

Considerou-se germinação o período entre o entumescimento da semente até a liberação dos cotilédones, antes que os eófilos estivessem totalmente formados; e plântula, a fase de desenvolvimento em que os eófilos estavam totalmente formados. A definição de eófilo e metáfilo foi feita com base na análise da planta matriz, levando-se em consideração o conceito de Duke e Polhill (1981). Para o processo germinativo e para a morfologia da plântula, utilizou-se vermiculita em bandeja de plástico com $80 \times 40 \times 20 \mathrm{~cm}$.

A metodologia e a terminologia empregadas estão de acordo com os trabalhos de Martin (1946), Systematics Association Committee for Descriptive Terminology (1962), Font-Quer (1963), Duke (1965, 1969), Van der Pilj (1972), Radford et al. (1974), Kuniyoshi (1983), Roderjan (1983), Van Roosmalem (1985), Stern (1992), Oliveira (1993), Barroso et al. (1999) e Gurgel (2000).

Os frutos, as sementes e as fases do desenvolvimento, desde a emissão da radícula até a completa formação dos eófilos, foram fotografados. O material vegetativo, relacionado ao processo germinativo e as plântulas, foram desidratados em estufa para posterior confecção de exsicatas, com as suas respectivas etiquetas. As amostras foram incorporadas sob os números MG 168.216 (Gurgel, E.S.C., 174) e IAN 168216 (Carvalho, A.C.M., 90).

Os caracteres morfológicos dos frutos e sementes, do processo germinativo e de plântulas foram ilustrados com fotografias. As fotografias foram feitas em lupa Zeiss Stemi SV6, com capturador de imagem digital sound vision SV micro adaptado e máquina fotográfica digital Nikon DIX.

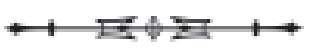




\section{RESULTADOS}

\section{Morfologia do fruto}

Estenocárpico, seco, do tipo cápsula, elíptica a oblonga, comprimida em direção perpendicular ao eixo, ápice e base obtusos (Tabela 1). Externamente, o pericarpo, quando imaturo, é verde e, quando maduro, opaco e em tons castanhos quase negro (Figura 1a); é glabro e cartáceo, internamente lustroso e em tons castanhos claro, com base levemente agudo, ápice arredondado e ligeiramente obtuso (Figura 1b). Não possui estipete, nem tampouco torção em suas valvas; as nervuras de suas margens não são constrictas e não ornamentadas. É um fruto com deiscência loculicida. A abertura inicial das valvas ocorre ao longo de ambas as suturas e após a deiscência; as valvas que não se contorcem permanecem presas ao pedúnculo. As sementes não são visíveis externamente. $\bigcirc$ eixo seminífero é curto assim como o funículo (Figura 1c e 2a), divide-se ao meio após a deiscência, ficando as suas porções presas às valvas, trata-se, ainda, de um fruto com uma média de 6 a 8 séries de sementes (Figura 1d) e, conseqüentemente, polispérmico. Apresentando tons castanhos, o pedúnculo é cilíndrico e mais espesso na base, glabro, com consistência lenhosa.

\section{Morfologia da semente}

Descrição externa: asa hialina, membranácea com estriais radiais, em tons castanhos, que partem da região embrionária (Figura 2a e 2b); estenospérmica, núcleo seminífero cordiforme (Figura 2b), com ápice arredondado e base lobada. Testa monocrômica, em tons castanhos, opaca, esponjosa desidratada e, quando hidratada, sem depressões; superfície glabra e rugosa. Região hilar próxima ao ápice da radícula, hilo punctiforme, heterócromo, castanho mais claro que a testa, em depressão; micrópila não perceptível (Tabela 2).

Descrição interna: tégmen castanho-claro e membranáceo. Endosperma ausente. Embrião alargado, axial, foliáceo, invaginado, amarelo. Quanto à posição dos cotilédones em relação ao eixo hipocótilo radícula, observa-se que são pleurorrizos e acumbentes. Os cotilédones são planos a levemente convexos, crassos, esbranquiçados, dominantes, cordiformes, ápice profundamente bilobado, margem inteira, base arredondada, auriculado com a radícula exposta, unidos somente ao ápice do eixo hipocótilo-radícula; quando abertos e ao remover-se o eixo embrionário observase uma depressão impressa deixada pela plúmula no centro de um dos cotilédones. Eixo embrionário entre os lóbulos cotiledonares, reto, cônico, espesso, perolado; plúmula amarela, rudimentar.

\section{Morfologia da germinação}

Fanerocotiledonar, epígea, emergência inicialmente reta e posteriormente curvada. Com a reidratação a semente não se entumesce muito (Figura 2a), portanto, não aumenta significativamente o seu volume. Doze dias após a semeadura, a radícula rompe o tegumento abaixo da região hilar, inicialmente cilíndrica, curta, glabra, amarelo esbranquiçada e, à medida que ocorre o seu alongamento, adquire cor castanho (Figura 2b). Coleto não evidenciado, observa-se apenas uma diferença de cor entre a radícula e o hipocótilo. Hipocótilo inicialmente curvo e posteriormente reto, verde, grande, cilíndrico, subherbáceo, com muitos tricômas simples, curtos, hialinos e retos e com tricômas captados (ferruginosos). Cotilédones verdes (Figura 2b), profundamente auriculados, com lâminas paralelas, isófilos, unilaterais, crassos, nervuras não

Tabela 1. Dimensões (cm), desvio padrão e coeficiente de variação (C.V.) dos frutos de Jacaranda copaia subsp. spectabilis.

\begin{tabular}{llllll}
\hline & Máximo & Média & Mínimo & Desvio Padrão & C.V. (\%) \\
\hline Comprimento & 10,90 & 9,582 & 8,20 & 0,660 & 6,887 \\
Largura & 4,67 & 4,141 & 1,25 & 0,579 & 13,972 \\
Espessura & 1,57 & 1,344 & 1,14 & 0,144 & 8,506 \\
\hline
\end{tabular}

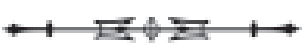


Jacaranda copaia (Aubl.) D. Don. subsp. spectabilis (Mart. ex A. DC) Gentry (Bignoniaceae): aspectos morfológicos...

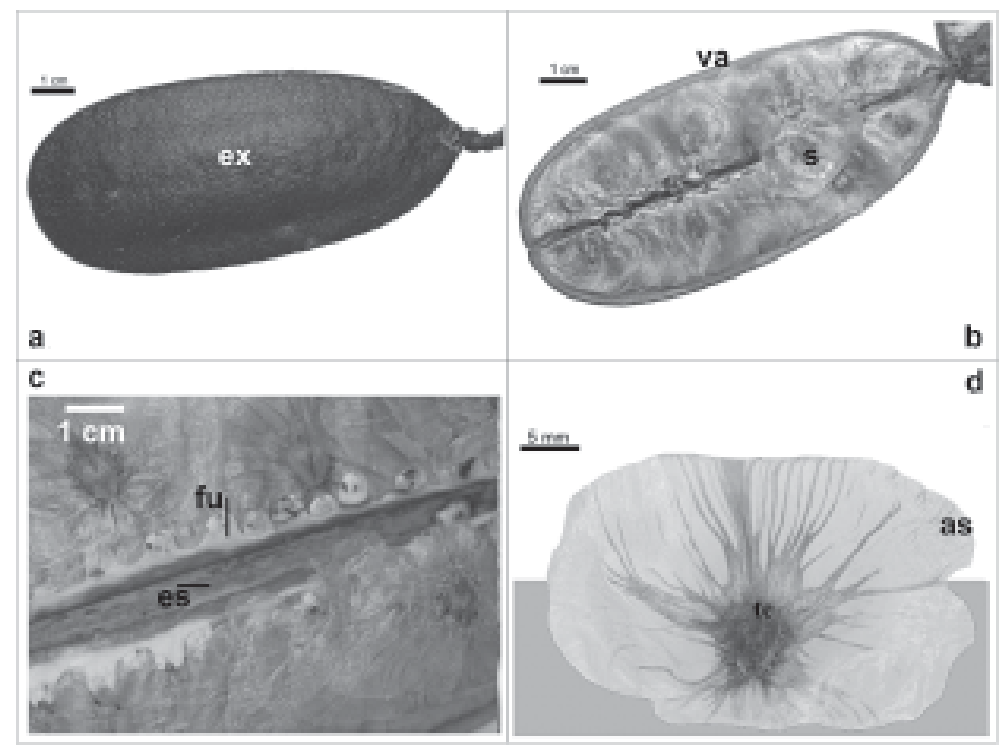

Figura 1. Jacaranda copaia subsp. spectabilis. Detalhes do fruto e da semente: a) Fruto maturo; b) secção longitudinal do fruto; c) semente ligada ao fruto pelo funículo; d) semente inteira. as-asa; es-eixo seminífero; ex-exocarpo; fu-funículo; s-semente; te-testa; va-valva.

evidentes, em um só plano, prefolheação valvar, opostos quando totalmente abertos, superfície abaxial com tricômas glandulares com ápice castanho ferruginoso glabro e a adaxial com poucos tricômas hialinos, reduzidos, adpressos e simples nas margens; pulvino e pecíolo reduzidos, achatados, também com poucos tricômas simples, hialinos e retos, semelhantes aos das lâminas dos cotilédones

\section{Morfologia da plântula}

Sistema radicular pivotante, raiz primária axial, cilíndrica, sinuosa, subherbácea, crassa, delgada, com muitas ramificações, em tons castanhos, formando um conjunto, irregular, raízes secundárias pouco ramificadas, irregularmente distribuídas (Figura 2c), no ápice das raízes laterais observa-se à presença de muitos tricômas ferrugineos e captados. Coleto lateralmente expandido (unilateral), verde, com poucos tricômas simples, hialinos, curtos e retos (Figura 2c). Hipocótilo, epígeo, cilíndricos, verde, estriado e com muitos tricômas hialinos simples, retos e tricômas glandulares captados (ferrugíneo). Epicótilo verde, cilíndrico, longo com muitos tricômas simples e semelhantes aos do hipocótilo e com poucos tricômas captados. Eófilos trifoliolados, opostos, simétricos, discolores, face adaxial mais escura que abaxial, ovais, margem crenada, com tricômas hialinos e simples por todo o limbo, pecíolo canaliculado. Na planta jovem, os eófilos de $2^{\mathrm{a}}$ ordem são imparipinados (Figura 2d), com cinco folíolos, discolores, face adaxial mais escura que abaxial, filotaxia oposta e cruzada.

Tabela 2. Dimensões (cm), desvio padrão e coeficiente de variação (C.V.) das sementes de Jacaranda copaia subsp. spectabilis.

\begin{tabular}{llllll}
\hline & Máximo & Média & Mínimo & Desvio Padrão & C.V. (\%) \\
\hline Comprimento & 2,98 & 2,658 & 2,14 & 0,171 & 6,415 \\
Largura & 1,65 & 1,412 & 1,04 & 0,169 & 11,964 \\
Espessura & 0,15 & 0,117 & 0,09 & 0,016 & 13,731 \\
\hline
\end{tabular}

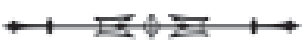




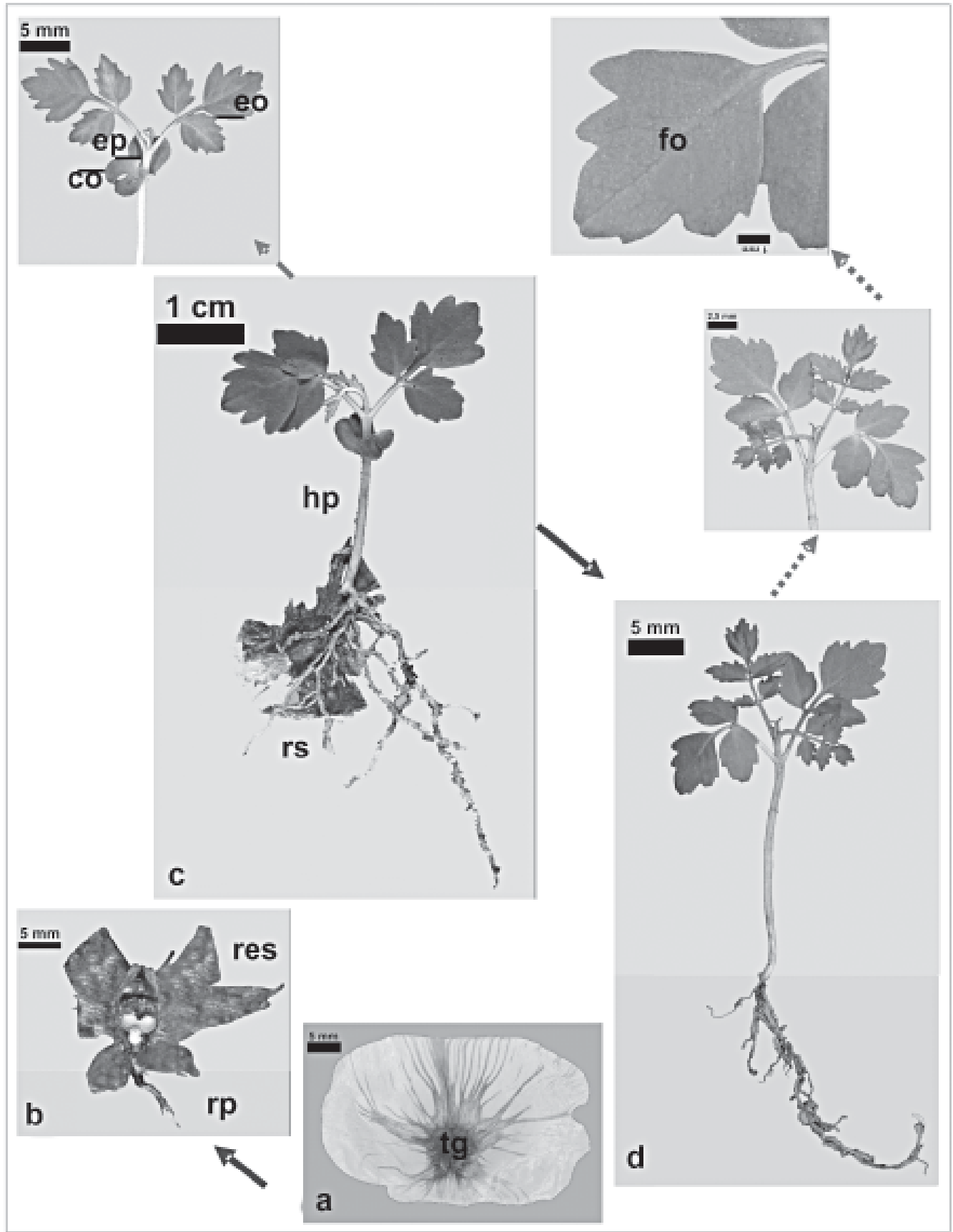

Figura 2. Jacaranda copaia subsp. spectabilis. Detalhes do processo germinativo, da plântula e da planta jovem: a) semente inteira; b) raiz primária alongada, 14 dias após a semeadura; c) plântula, 23 dias após a semeadura; d) planta jovem, 1 mês e 7 dias após a semeadura. Co-cotilédone; eo-eófilo; fo-folíolo; ep-epicótilo; hp-hipocótilo; res-restos seminais; rp-raiz primária; rs-raiz secundária; tg-tegumento.

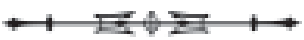


Jacaranda copaia (Aubl.) D. Don. subsp. spectabilis (Mart. ex A. DC) Gentry (Bignoniaceae): aspectos morfológicos...

\section{DISCUSSÃO E CONCLUSÃO}

Segundo Barroso et al. (1999) e Gentry e Morawetz (1992), o fruto de Jacaranda é originado de um ovário súpero, sendo geralmente uma cápsula não equinada, mais ou menos orbicular a elíptica, comprimida, ápice e base obtusos, com eixo seminífero muito reduzido, e que se rompe por ocasião da deiscência, deixando cada metade presa às valvas. As sementes são presas ao fruto pela base, isto é, na região hilar, apresentando asa hialina e núcleo seminífero, não possuem endosperma, o embrião é mais largo do que longo, os cotilédones são geralmente emarginados e o eixo hipocótilo radícula é curto. Tal resultado pode ser confirmado no estudo de J. copaia subsp. spectabilis, no qual se observou fruto do tipo cápsula, elíptica, cuja semente apresenta embrião semelhante ao descrito pelos autores.

J. copaia subsp. spectabilis apresenta germinação fanerocotiledonar epígea, com cotilédones bilobulados e auriculados, o mesmo observado por Duke (1969) para Bignoniaceae, onde ressalta que a germinação é geralmente fanerocotiledonar, com a presença de cotilédones estreita a largamente reniforme, profundamente emarginado a bilobado, cordato a auriculado.

Segundo Duke (1965), cotilédones retusos e sem nervuras são característicos em Bignoniaceae, o que pôde ser observado em J. copaia subsp. spectabilis, uma vez que os cotilédones são profundamente lobados e sem nervuras.

\section{REFERÊNCIAS}

BARROSO, G. M. et al. 1999. Frutos e sementes: morfologia aplicada à sistemática de dicotiledôneas. Viçosa: Editora UFV, Universidade Federal de Viçosa. 443 p.

CORRÊA, M. P. 1984. Dicionário das Plantas Úteis do Brasil e das Exóticas Cultivadas. Rio de Janeiro: Imprensa Nacional, 1926-1978. v. 2. Ministério da Agricultura. Instituto Brasileiro de Desenvolvimento Florestal. 707 p.
DUKE, J. A. 1965. Keys for the identification of seedlings of some proeminent woody species in eight forest types in Puerto Rico. Ann. Missouri Bot. Gard., v. 52, n. 3, p. 314-350.

DUKE, J. A. 1969. On tropical tree seedlings, systems and systematics. Ann. Missouri Bot. Gard., v. 56, n. 2, p. 135-161.

DUKE, J. A.; POLHILL, R. M. 1981. Seedlings of Leguminosae. In: POLHILL, R. M.; RAVEN, P. H. (Ed.). Advances in Legumes Systematics. England: Royal Bot. Garden, Kew, Richmond, Surrey. p. $941-949$. v. 2.

FONT-QUER, P. 1963. Dicionário de Botânica. Barcelona: Labor. $1244 \mathrm{p}$.

GENTRY, A.; MORAWETZ, W. 1992. Bignoniaceae. (Tribe Tricomeae) Flora Neotropica, New York, v. 25, n. 2. Botanical Garden.

GURGEL, E. S. C. 2000. Morfologia de frutos, sementes, germinação e plântulas de leguminosas presentes em uma vegetação de mata secundária na Amazônia Central. 160 f. Dissertação (Mestrado) - INPA/UA, Manaus.

KUNIYOSHI, Y. S. 1983. Morfologia da semente e da germinação de 25 espécies arbóreas de uma floresta com araucária. 232 f. Dissertação (Mestrado) - Universidade Federal do Paraná, Curitiba, Paraná.

MARTIN, A. C. 1946. The comparative internal morphology of seeds. Am. Midl. Nat., v. 36, n. 3, p. 513-660.

OLIVEIRA, E. C. 1993. Morfologia de plântulas florestais. In: AGUIAR, I. B.; PIÑA-RODRIGUES, F. C. M.; FIGLIOLA, M. B. Sementes florestais tropicais. Brasília: ABRATES. p. 175-214.

RADFORD, A. E. et al. 1974. Vascular plants systematics. New York: Harper and Row. 877 p.

RIBEIRO, J. E. L. S. et al. 1999. Flora da reserva Ducke: guia de identificação de plantas vasculares de uma floresta de terra-firme na Amazônia Central. Manaus: INPA. 816 p.

RODERJAN, C. V. 1983. Morfologia do estádio juvenil de 24 espécies arbóreas de uma floresta com araucária. $148 \mathrm{f}$ Dissertação (Mestrado) - Universidade Federal do Paraná, Curitiba, Paraná.

SILVA, M. F. da; LISBOA, P. L. B.; LISBOA, R. C. L. 1977. Nomes Vulgares de Plantas Amazônicas. Belém: INPA.

STERN, W. T. 1992. Botanical latin. history, grammar, syntax, terminology and vocabulary. New York: Ed. Hafner Publishing Company. 566 p.

SYSTEMATICS ASSOCIATION COMMITTEE FOR DESCRIPTIVE TERMINOLOGY. 1962. Terminology of simple symmetrical plane shapes (chart 1). p. 104-109. (Taxon, 9).

VAN DER PIJL, L. 1972. Principles of dispersal in higher plants. Berlin: Springer Verlag. $162 \mathrm{p}$.

VAN ROOSMALEN, M. G. M. 1985. Fruits of the Guianan Flora. Neetherlands: Utretcht Institute of Systematic Botany, Utretcht University. $483 \mathrm{p}$.

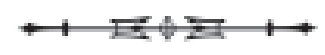

